\title{
PENERAPAN REVENUE SHARING CONTRACT PADA KLASTER INDUSTRI
}

\author{
NURWIDIANA \\ Jurusan Teknik Industri, Fakultas Teknologi Industri, Universitas Islam Sultan Agung \\ E-mail: nur_widiana@yahoo.com
}

\begin{abstract}
ABSTRAK
Klaster industri adalah konsentrasi geografis dari perusahaan dan industri yang saling berkompetisi, komplementer, atau saling terkait, yang melakukan bisnis satu dengan lainnya dan/atau memiliki kebutuhan serupa akan kemampuan, teknologi dan infrastruktur. Dalam sebuah klaster industri, maka hubungan antara industri-industri tersebut harus saling menguntungkan. Namun tanpa adanya kontrak ada kalanya Industri Kecil Menengah (IKM) yang berperan sebagai produsen, tidak memiliki posisi tawar yang kuat dibandingkan dengan distributor selaku industri pendukung, sehingga seringkali IKM dirugikan. Penelitian ini akan fokus pada analisis kontrak sebagai upaya koordinasi dalam sebuah klaster industri makanan ringan. Analisis dilakukan terhadap penerapan model revenue sharing contract. Pada model revenue sharing contract, produsen menetapkan harga jual yang rendah (minimal) kepada distributor untuk tiap unit yang dibeli, tetapi distributor harus membagi sebagian (fraksi) keuntungan untuk tiap unit yang terjual. Dari hasil penelitian diketahui bahwa dengan menerapkan model revenue sharing, biaya overstock dapat ditekan sehingga kuantitas pesan dari distributor meningkat dan akhirnya mampu meningkatkan keuntungan baik bagi IKM maupun distributor. Agar revenue sharing contract menghasilkan keuntungan yang optimal perlu ditetapkan nilai proporsi pembagian keuntungan (f) yang tepat. Untuk menerapkan model kontrak ini diperlukan keterbukaan informasi antara IKM dan distributor.
\end{abstract}

Kata kunci: klaster, IKM, kontrak, revenue sharing

\begin{abstract}
Industry cluster are geographic concentrations of competing, complementary, or interdependent firm and industries that do business with each other and/or have common needs for talent, technology, and infrastructure. In a industry cluster, the relationship should be profitable for each other. However, in the absence of contract, Small Medium Enterprises (SMEs) as producers, do not have a strong bargaining position compared to a distributor as supporting industry so that SMEs are frequently lost. This research focus on the revenue sharing contract as an effort of coordination in snacks industry cluster. In the revenue sharing contract the manufacturer charges the distributor a low price and shares a fraction fof revenue generates by distributor. Based on the analysis has been performed, implementing revenue sharing model, can reduce the overstock cost so that it can increase the quantity orders from distributors and finally increase profits for both the SMEs and distributor. In order to gain optimum profit, it is needed to set the fraction ( $f$ ) of profit sharing on revenue sharing contract. The implementation of this model requires information sharing between the SMEs and distributor.
\end{abstract}

Key words: cluster, SMEs, contract, revenue sharing

\section{PENDAHULUAN}

Peran usaha kecil dan menengah (IKM) dalam menggerakkan sektor riil merupakan kegiatan ekonomi nasional yang sangat penting dan strategis. Oleh karenanya penguatan terhadap ekonomi skala kecil dan menengah dipandang perlu menjadi prioritas yang harus dilakukan untuk menopang ekonomi nasional yang kuat dan terciptanya fundamental ekonomi yang tangguh. Salah satu upaya yang dilakukan dalam rangka pengembangan dan penguatan IKM adalah dengan pembentukan Klaster Industri. Klaster industri adalah konsentrasi geografis dari perusahaan dan industri yang saling berkompetisi, komplementer, atau saling terkait, yang melakukan bisnis satu dengan lainnya dan/ atau memiliki kebutuhan serupa akan kemampuan, teknologi dan infrastruktur (Munnich et al., 1999). Dalam sebuah klaster industri, maka hubungan antara industri-industri tersebut harus saling menguntungkan. Oleh sebab itu maka sebuah klaster industri dapat juga dipandang sebagai sebuah rantai pasok. Melalui cara pandang manajemen rantai pasok, maka keputusan-keputusan yang diambil harus menguntungkan keseluruhan pemain yang 
ada di dalamnya (Burt \& Starling, 2003). Namun ada kalanya di sebuah klaster industri, IKM yang berperan sebagai produsen tidak memiliki posisi tawar yang kuat dibandingkan dengan distributor selaku industri pendukung. Hal yang sering terjadi adalah distributor menentukan harga beli dari IKM dan dengan harga tertentu menjualnya ke konsumen. IKM tidak memiliki intervensi pada penentuan harga jual dari distributor ke konsumen sehingga seringkali harga jual tersebut jauh lebih mahal di banding dengan harga beli distributor dari IKM. Hal tersebut berakibat tingkat penjualan produk tidak bisa maksimal. Selain itu pihak distributor juga seringkali melakukan pengembalian barang yang tidak laku ke IKM tanpa ada batasan jumlah pengembalian. Dengan kondisi tersebut jelas pihak distributor lebih diuntungkan dibanding pihak produsen. Untuk mengatasi hal tersebut perlu adanya mekanisme yang mengatur hubungan kerja sama antar industri dalam klaster sehingga kerja sama yang terjalin akan mampu memberikan keuntungan bagi semua pihak dan pada akhirnya akan mampu menguatkan klaster industri yang ada.

Penelitian ini akan fokus pada mekanisme kontrak sebagai upaya koordinasi dalam sebuah klaster industri makanan ringan. Koordinasi yang akan dibahas adalah antara IKM sebagai industri inti dalam sebuah klaster industri pangan dengan perusahaan distributor selaku industri pendukung yang memiliki peranan sebagai pihak yang memasarkan produk yang dihasilkan IKM.

Dalam manajemen rantai pasok dikenal adanya beberapa model kontrak yang mengatur hubungan kerja sama antara industri-industri yang ada dalam sebuah jaringan. Di antaranya yaitu buy back contracts (Pasternack, 1985), quantity flexibility contract (Tsay, 1999), sales rebates contract (Taylor, 2002) dan revenue sharing contract (Dana and Spier, 2001). Dari ke empat model kontrak tersebut, revenue sharing contract mampu membangun koordinasi yang baik dalam rantai pasok (Cachon and Lariviere, 2005). Pada model revenue sharing contract maka produsen menetapkan harga jual yang rendah (minimal) kepada distributor untuk tiap unit yang dibeli, tetapi distributor harus membagi sebagian (fraksi) pendapatan untuk tiap unit yang terjual (Chopra and Meindl, 2001).

Berdasarkan penelitian Cachon dan Lariviere (2001) maka penelitian ini akan menerapkan model revenue sharing contract pada klaster industri. Dengan model revenue sharing contract yang dikembangkan oleh Chopra dan Meindl (2001) akan di tentukan parameter kontrak yang dapat memberikan peningkatan keuntungan baik bagi IKM, distributor serta klaster. Pembahasan pada penelitian ini dibatasi pada hubungan antara IKM (industri inti) dan distributor (industri pendukung).

\section{METODE}

Penelitian ini mengambil objek Klaster Industri Makanan Ringan "KARYA BOGA" yang berlokasi di Kota Magelang. Dilakukan pengamatan langsung ke lapangan dan pengumpulan data meliputi: karakteristik produk dari anggota klaster, kontrak yang diterapkan antara IKM dan distributor dalam klaster tersebut, tingkat permintaan produk pada distributor serta harga jual barang dari IKM ke distributor dan harga jual dari distributor ke konsumen akhir.

Dari data-data yang diperoleh akan dilakukan pengolahan data untuk mengetahui performansi model kontrak yang saat ini digunakan dan performansi jika menerapkan model revenue sharing contract. Dengan model revenue sharing contract maka manufacturer yang memproduksi dengan biaya $\mathrm{v}$ per unit dan menjualnya dengan harga rendah yaitu c kepada retailer. Retailer kemudian menjualnya dengan harga $\mathbf{p}$ dan akan membagi keuntungannya kepada manufacture dengan fraksi f untuk masingmasing unit yang telah terjual. Jika ada barang yang tersisa di distributor maka masih memiliki nilai sebesar Sr. Retailer akan menentukan ukuran pesannya berdasarkan pada service level berdasarkan biaya overstock $(\mathrm{Co})$ dan biaya understock $(\mathrm{Cu})$ (Chopra and Meindl, 2001).

Customers Service Level CSL $=\frac{C u}{C u+C o}$

Di mana $\mathrm{Cu}=(1-\mathrm{f}) \mathrm{p}-\mathrm{c}$ dan $\mathrm{Co}=(1-\mathrm{f}) \mathrm{p}-\mathrm{sr}$

Berdasarkan nilai CSL tersebut, jika diketahui tingkat permintaan rata-rata sebesar $\mu$ dengan standar deviasi $\sigma$, maka jumlah pesanan yang optimal ditentukan dengan rumus:

$Q^{*}=F^{-1}\left(C S L^{*}, \mu, \sigma\right)=\operatorname{NORMINV}\left(C S L^{*}, \mu, \sigma\right) \ldots(2)$

Dengan menetapkan ukuran pesan pada nilai $Q^{*}$, maka ekspektasi keuntungan di masing-masing pihak dapat dihitung sebagai berikut:

Ekpektasi keuntungan pada manufacturer

$=(\mathrm{c}-\mathrm{v}) \mathrm{Q}^{*}+\mathrm{fp}\left(\mathrm{Q}^{*}\right.$ - ekspetasi overstock pada distributor)

Ekpektasi keuntungan pada distributor

$=(1-\mathrm{f}) \mathrm{p}\left(\mathrm{Q}^{*}-\right.$ Ekspetasi overstock distributor $)+$ $\mathrm{SR} \times \mathrm{x}$ ekspetasi overstock distributor $-\mathrm{cQ}^{*}$........ (4) 
Di mana ekspektasi overstock (EOS) distributor adalah

$$
\operatorname{EOS}_{R}=\left(Q^{*}-\mu\right) F s\left(\frac{Q^{*}-\mu}{\sigma}\right)+\sigma f s\left(\frac{Q^{*}-\mu}{\sigma}\right) \ldots \ldots .(5)
$$

\section{Ekspektasi Keuntungan Supply Chain}

= Ekspektasi Keuntungan Manufacturer + Ekspektasi Keuntungan Distributor.

Dari hasil pengolahanan data, akan dianalisa bagaimana performansi model revenue sharing contract dibandingkan dengan model kontrak yang saat ini diterapkan. Performansi yang dianalisa meliputi: keuntungan pada IKM, keuntungan pada distributor dan keuntungan total supply chain. Selanjutnya juga akan dianalisa parameterparameter apa saja yang memengaruhi performansi kontrak sehingga dapat menentukan parameter yang mampu meningkatkan kinerja klaster.

\section{HASIL DAN PEMBAHASAN}

Klaster IKM Makanan Ringan Kota Magelang terbentuk pada pertengahan tahun 2010. Saat ini klaster tersebut memiliki anggota 25 IKM dengan beragam produk makanan sebagai industri inti, Karya Boga sebagai distributor, Bank Mandiri dan BRI sebagai lembaga keuangan, FEDEP dan Diskoperindag sebagai Instansi pemerintah.

Dengan terbentuknya klaster ini, maka IKM anggota klaster sebagai industri inti menjalin kerja sama dengan Karya Boga sebagai distributor dalam melakukan pemasaran produknya. Selama ini terdapat dua model mekanisme pemasaran yang diterapkan, yaitu model jual lepas dan model konsinyasi. Model yang diterapkan sangat tergantung kesepakatan antara pemilik IKM dengan pihak Karya Boga.

Dengan model jual lepas, IKM makanan ringan akan mengirimkan produk dengan jumlah dan jenis sesuai permintaan Karya Boga sebagai distributor. IKM sebagai produsen hanya menetapkan harga jual ke Karya Boga, selanjutnya harga jual dari distributor ke konsumen akhir sepenuhnya menjadi kewenangan Karya Boga sebagai distributor. Untuk model ini IKM tidak menerima adanya pengembalian produk dari Karya Boga, sehingga resiko kelebihan produk ditanggung oleh Karya Boga. Sedangkan dengan model konsinyasi IKM menitipkan produknya ke distributor dan sudah menetapkan harga jual ke konsumen. Produk yang tidak habis terjual akan dikembalikan ke IKM, distributor hanya membayar sebanyak produk yang laku, tanpa ada batasan maksimal berapa produk
Tabel 1. Tingkat Permintaan Produk

\begin{tabular}{lccr}
\hline \multirow{2}{*}{ Produk } & \multirow{2}{*}{ Kode } & \multicolumn{2}{c}{ Permintaan $(\mathbf{K g})$} \\
\cline { 3 - 4 } & & Rata-rata & Stdev \\
\hline Keripik Tahu & KTh & 7415 & 1434 \\
Keripik Tempe & KTp & 2959 & 547 \\
Keripik Singkong & KS & 5010 & 765 \\
Selondok & SLD & 2092 & 731 \\
Keripik Jamur & KJ & 131 & 33 \\
Kacang Telur & KcT & 200 & 79 \\
Keripik Paru & KP & 71 & 11 \\
Bolu Panggang & BP & 3960 & 291 \\
\hline
\end{tabular}

yang boleh dikembalikan. Tabel 1. menampilkan jenis produk dan tingkat permintaan mingguan dari tiaptiap jenis produk yang diterima oleh Karya Boga selama 1 tahun terakhir.

Pada model kontrak yang saat ini diterapkan, IKM memproduksi barang dengan biaya produksi sebesar v, kemudian menjual ke Karya Boga dengan harga c. Selanjutnya Karya Boga menjual ke konsumen dengan harga p seperti ditunjukkan pada gambar 1. Meskipun untuk tiap satu jenis produk dihasilkan oleh beberapa IKM namun sesuai konsep klaster maka diupayakan adanya keseragaman produk. Dengan demikian biaya produksi dan harga jual untuk produk yang sejenis akan sama, seperti ditunjukkan pada tabel 2 . Untuk barang yang tidak terjual diasumsikan sudah tidak memiliki nilai sisa, karena untuk produk makanan jika sudah melewati masa kadaluwarsanya maka harus ditarik dari peredaran dan dimusnahkan.

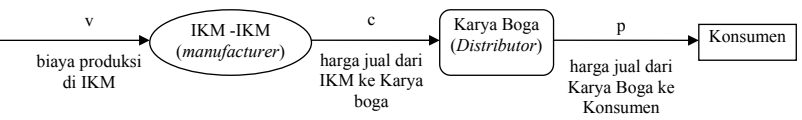

Gambar 1. Struktur Supply Chain dan Biaya dalam Klaster

Tabel 2. Harga Produk

\begin{tabular}{lcrc}
\hline \multirow{2}{*}{$\begin{array}{c}\text { Kode } \\
\text { Produk }\end{array}$} & $\begin{array}{c}\text { Biaya produksi } \\
\text { (Rp.000/kg) }\end{array}$ & \multicolumn{2}{c}{ Harga Jual (Rp.000/kg) } \\
\cline { 3 - 4 } & $\mathbf{v}$ & $\mathbf{c}$ & $\mathbf{p}$ \\
\hline KTh & 10 & 20 & 30 \\
KTp & 10 & 21 & 35 \\
KS & 8 & 15 & 20 \\
SLD & 10 & 15 & 23 \\
KJ & 30 & 50 & 75 \\
KcT & 20 & 25 & 35 \\
KP & 60 & 100 & 150 \\
BP & 10 & 20 & 30 \\
\hline
\end{tabular}


Karya Boga memesan sejumlah Q kepada IKM untuk memenuhi permintaan konsumen berdasarkan nilai Customer Service Level yang ditetapkan. Penetapan nilai Customer Service Level (CSL) dengan mempertimbangkan biaya kelebihan persediaan/overstock (Co) dan biaya kekurangan persediaan/understock $(\mathrm{Cu})$ pada karya boga, di mana $\mathrm{Cu}=\mathrm{p}-\mathrm{c}$, dan $\mathrm{Co}=\mathrm{c}-\mathrm{s}$. Berdasarkan nilai CSL tersebut, jika diketahui tingkat permintaan rata-rata sebesar $\mu$ dengan standar deviasi $\sigma$, maka jumlah pesanan yang optimal ditentukan dengan rumus (2). Dengan jumlah pemesanan sebesar $Q^{*}$, maka dapat diperkirakan nilai keuntungan yang akan diterima IKM dan Karya Boga sehingga total keuntungan yang diperoleh klaster dapat diketahui.

\section{Ekspektasi Keuntungan IKM}

$\mathrm{EP}_{\text {IKM }}=\mathrm{Q}^{*}(\mathrm{c}-\mathrm{v})$

Ekspektasi Keuntungan Karya Boga

$$
\begin{aligned}
& E P_{K B}=(p-s) \mu F s\left(\frac{Q^{*}-\mu}{\sigma}\right)-(p-s) \sigma f s\left(\frac{Q^{*}-\mu}{\sigma}\right) \\
& -Q^{*}(c-s) F\left(Q^{*}, \mu, \sigma\right)+Q^{*}(p-c)\left(1-F\left(Q^{*}, \mu, \sigma\right) \ldots\right.
\end{aligned}
$$

Ekspektasi keuntungan Klaster dihitung dengan formula (5).

Untuk produk Keripik tahu (KTh) yang permintaan rata-rata $(\mu)=7415$ dan $\sigma=1434$, dengan nilai $\mathrm{v}=10, \mathrm{c}=20$ dan $\mathrm{p}=30$, maka dapat dihitung nilai $\mathrm{Cu}=\mathrm{p}-\mathrm{c}=10$ dan, $\mathrm{Co}=\mathrm{c}-\mathrm{s}=20$, sehingga tingkat service level.

$$
\mathrm{CSL}=\frac{\mathrm{Cu}}{(\mathrm{Cu}+\mathrm{Co})}=\frac{10}{10+20}=0,3333=33,33 \%
$$

Jumlah pemesanan

$$
\begin{aligned}
Q^{*} & =F^{-1}(33,33 \%, 7415,1434) \\
& =\operatorname{NORMINV}(33,33 \%, 7415,1434)=6797
\end{aligned}
$$

\section{Ekspektasi Keuntungan IKM}

$$
\begin{aligned}
\mathrm{EP}_{\text {IKM }} & =\mathrm{Q}^{*}(\mathrm{c}-\mathrm{v}) \\
& =6797(20-10)=\text { Rp.67.970 }
\end{aligned}
$$

Ekspektasi Keuntungan Karya Boga $\left(\mathrm{EP}_{\mathrm{KB}}\right)$

$$
\begin{aligned}
= & (30-0) \mu \mathrm{Fs}\left(\begin{array}{c}
6797-7415 \\
1434
\end{array}\right)-(30-0) 1434 \mathrm{fs}\left(\begin{array}{c}
6797-7415 \\
1434
\end{array}\right) \\
& -6797(20-0) \mathrm{F}(8033,7415,1434)+6797(30-20) \\
& (1-\mathrm{F}(67977415,1434)=58508
\end{aligned}
$$

Dengan excel dapat diformulasikan:

$\begin{aligned}= & (30-0) \mu \text { NORMDIST }\left(\left(\begin{array}{c}6797-7415 \\ 1434\end{array}\right), 0,1,1\right) \\ & -\left(30 \text { - 0)11434NORMDIST }\left(\left(\begin{array}{c}6797-7415 \\ 1434\end{array}\right), 0,1,0\right)\right.\end{aligned}$

- 8033(20 - 0)NORMDIST $(6797,7415,1434,1)+$

$8033(30-20)(1-$ NORMDIST $(6797,7415,1434,1)=58508$

Ekspektasi keuntungan Klaster

$\mathrm{EP}$ Klaster $=\mathrm{EP}$ IKM $+\mathrm{EP} \mathrm{KB}$

$$
=\text { Rp. } 67.970+\text { Rp. } .58 .508=\text { Rp. } 126.478
$$

Hasil perhitungan untuk produk yang lain ditampilkan pada tabel 3.

Tabel 3. Performansi Mekanisme Kontrak Saat ini

\begin{tabular}{lcrrrr}
\hline \multirow{2}{*}{$\begin{array}{l}\text { Kode } \\
\text { Prod }\end{array}$} & CSL & $\mathbf{Q}^{*}$ & \multicolumn{3}{c}{ Ekpektasi Profit (Rp.000) } \\
\cline { 4 - 6 } & & & IKM & $\begin{array}{c}\text { Karya } \\
\text { Boga }\end{array}$ & Klaster \\
\hline KTh & 0,33 & 6797 & 67.973 & 58.508 & 126.481 \\
KTp & 0,40 & 2820 & 31.025 & 34.029 & 65.054 \\
KS & 0,25 & 4494 & 31.458 & 20.188 & 51.646 \\
SLD & 0,35 & 1806 & 9.030 & 10.523 & 19.553 \\
KJ & 0,33 & 117 & 2.336 & 2.375 & 4.711 \\
KcT & 0,29 & 155 & 776 & 1.060 & 1.837 \\
KP & 0,33 & 66 & 2.650 & 2.950 & 5.601 \\
BP & 0,33 & 3835 & 38.347 & 36.426 & 74.772 \\
\hline
\end{tabular}

Hasil pada tabel 3 diperoleh saat service level (CSL) ditentukan hanya berdasarkan biaya pada Karya Boga. Jika klaster tersebut dipandang sebagai sebuah rantai pasok (supply chain) maka penentuan service level harus mempertimbangkan seluruh biaya pada supply chain (Pujawan, 2005). Sebagai contoh untuk produk keripik tahu (KTh), dengan mempertimbangkan biaya di ke dua pihak, maka perhitungan service levelnya adalah sebagai berikut:

Biaya understock klaster

$\mathrm{Cu}=\mathrm{p}-\mathrm{v}=30-10=20$

Biaya overstock klaster

$\mathrm{Co}=\mathrm{v} \quad=10$

Tingkat service level

$C S L=\frac{C u}{(C u+C o)}=\frac{20}{20+10}=0,6667=66,67 \%$ 
Jumlah pemesanan

$$
\begin{aligned}
Q^{*} & =F^{-1}(66,67 \%, 7415,1434) \\
& =\operatorname{NORMINV}(66,67 \%, 7415,1434)=8033
\end{aligned}
$$

Ekspektasi Keuntungan IKM

$$
\begin{aligned}
\mathrm{EP}_{\text {IKM }} & =\mathrm{Q}^{*}(\mathrm{c}-\mathrm{v}) \\
& =8033(20-10)=\operatorname{Rp} .80 .330
\end{aligned}
$$

Ekspektasi Keuntungan Karya Boga $\left(\mathrm{EP}_{\mathrm{KB}}\right)$

$$
\begin{aligned}
= & (30-0) \mu F s\left(\begin{array}{c}
8033-7415 \\
1434
\end{array}\right)-(30-0) 1434 \\
& f_{S}\left(\begin{array}{c}
80336-7415 \\
1434
\end{array}\right)-8033(20-0) F(8033,7415,1434) \\
& +8033(30-20)(1-F(8033,7415,1434)
\end{aligned}
$$

Dengan excel dapat diformulasikan:

$$
\begin{aligned}
= & (30-0) \mu \text { NORMDIST }\left(\left(\begin{array}{c}
8033-7415 \\
1434
\end{array}\right), 0,1,1\right) \\
& -(30-0) 11434 \text { NORMDIST }\left(\left(\begin{array}{c}
8033-7415 \\
1434
\end{array}\right), 0,1,0\right) \\
& -8033(20-0) \text { NORMDIST }(8033,7415,1434,1) \\
& +8033(30-20)(1-\text { NORMDIST }(8033,7415,1434,1) \\
& =\text { Rp.52.331 }
\end{aligned}
$$

Ekspektasi keuntungan Klaster

$$
\text { EP Klaster }=\text { Rp.80.330+ Rp.52.331 }=\text { Rp. } 132.661
$$

Ternyata dengan mempertimbangkan biaya dari sudut pandang klaster mampu meningkatkan service level sehingga jumlah pesanan (Q) meningkat. Hal tersebut menyebabkan total keuntungan klaster meningkat, akibat peningkatan keuntungan pada IKM, namun sebaliknya keuntungan Karya Boga justru menurun. Untuk dapat mewujudkan peningkatan keuntungan klaster tersebut perlu dilakukan upaya agar peningkatan keuntungan yang dilakukan menghasilkan peningkatan keuntungan bagi IKM dan Karya Boga, tidak menyebabkan kerugian di salah satu pihak.

Untuk itu akan dianalisis revenue sharing contract sebagai upaya peningkatan keuntungan klaster. Untuk menerapkan perjanjian revenue sharing, maka IKM menjual produk dengan harga minimal pada Karya Boga. Pada kasus ini, ditetapkan harga jual ke Karya Boga sama dengan biaya produksi di IKM $(\mathbf{c}=\mathbf{v})$. Karya Boga menjual produknya dengan harga $p$ dan membagi keuntungannya dengan proporsi/ fraksi sebesar $f$ kepada IKM. IKM tidak menerima adanya pengembalian barang, dan diasumsikan tidak ada nilai sisa untuk produk yang tersisa di Karya Boga.

Sebagai contoh perhitungan untuk produk keripik tahu jika harga dari IKM (c) ditetapkan sama dengan biaya produksi $(\mathrm{v})=$ Rp.10.000 dan fraksi pembagian keuntungan (f) sebesar 5\%, maka

Biaya understock $\mathrm{Cu}=(1-\mathrm{f}) \mathrm{p}-\mathrm{c}=(1-0,05) * 30-10$ $=18,5$

Biaya overstock $\mathrm{Co}=\mathrm{c}-\mathrm{S}_{\mathrm{R}}=10-0=10$

Tingkat service level

$$
\mathrm{CSL}=\frac{\mathrm{Cu}}{(\mathrm{Cu}+\mathrm{Co})}=\frac{18,5}{18,5+10}=0,65=65 \%
$$

Jumlah pemesanan Karya Boga

$$
\begin{aligned}
Q^{*} & =F^{-1}(C S L, \mu, \sigma) \\
& =\operatorname{NORMINV}(065 \% 7415,1434)=7968
\end{aligned}
$$

Ekspektasi overstock di Karya Boga dihitung berdasarkan formulasi (5) dengan program excel dapat diformulasikan.

$$
\begin{gathered}
\text { EOS }_{R}=(7968-7415) \text { NORMDIST }\left(\left(\begin{array}{c}
7968-7415 \\
1434
\end{array}\right), 0,1,1\right) \\
+1434 \text { NORMDIST }\left(\left(\begin{array}{c}
7968-7415 \\
1434
\end{array}\right), 0,1,0\right)=891
\end{gathered}
$$

Ekspektasi Keuntungan IKM

$$
\begin{aligned}
\mathrm{EP}_{\text {IKM }} & =Q^{*}(c-v)+f p\left(Q^{*}-\operatorname{EOS}_{\mathrm{R}}\right) \\
& =7968(10-10)+0,05(307968-891=\text { Rp. } 10.614
\end{aligned}
$$

Ekspektasi Keuntungan Karya Boga

$$
\begin{aligned}
\mathrm{EP}_{\mathrm{KB}}= & (1-f) p\left(\mathrm{Q} *-\operatorname{EOS}_{\mathrm{R}}\right)+\left(\mathrm{S}_{\mathrm{R}} \mathrm{xEOS} \mathrm{R}_{\mathrm{R}}\right)-\mathrm{cQ} * \\
= & (1-0,05)(30)(7968-891)+(0 \times 891)- \\
& 10(7968)=\text { Rp.122.026 }
\end{aligned}
$$

Ekspektasi Keuntungan Klaster

$$
\begin{aligned}
\mathrm{EP}_{\mathrm{KL}} & =\mathrm{EP}_{\mathrm{IKM}}+\mathrm{EP}_{\mathrm{KB}} \\
& =\text { Rp.10.614 }+122.026=\text { Rp.132.640 }
\end{aligned}
$$

Jika revenue sharing contract ditetapkan pada nilai $f=0,05$ dan IKM menurunkan harga jual ke Karya Boga dari 20 menjadi 10, akibatnya biaya over stock di Karya Boga turun dari 20 menjadi 10 (lihat tabel 1). Penurunan biaya overstock tersebut menyebabkan nilai CSL Karya Boga meningkat dari $33,33 \%$ menjadi $65 \%$ sehingga jumlah pemesanannya $\left(Q^{*}\right)$ meningkat dari $6797 \mathrm{~kg}$ menjadi $7968 \mathrm{~kg}$. Hal tersebut menyebabkan peningkatan keuntungan 
bagi Klaster menjadi 105\% dari keuntungan semula akibat peningkatan keuntungan karya boga yang mencapai 209\%, namun kebalikannya keuntungan IKM menurun hingga $16 \%$. Hal ini terkait dengan pemilihan nilai f. Ini menunjukkan bahwa perlu penentuan nilai $f$ yang tepat agar penerapan revenue sharing contract mampu menghasilkan peningkatan keuntungan bagi semua pihak. Untuk itu dilakukan perhitungan revenue sharing pada beberapa nilai f, diperoleh hasil seperti ditunjukkan pada tabel 4.

Dari tabel 4 terlihat bahwa peningkatan nilai f menyebabkan peningkatan jumlah pesan yang menyebabkan peningkatan keuntungan bagi IKM. Namun bagi Karya Boga semakin besar nilai f keuntungannya makin kecil. Oleh karena itu maka penentuan nilai $f$ harus mempertimbangkan perubahan keuntungan di kedua pihak.

Pada produk keripik tahu nilai f sebaiknya ditetapkan pada nilai 0,35 (35\%). Karena pada nilai tersebut mekanisme revenue sharing ini menghasilkan peningkatan keuntungan bagi IKM sebesar 5\% dan bagi Karya Boga sebesar 1\% sehingga keuntungan klaster meningkat sebanyak $3 \%$. Nilai f yang lebih besar menghasilkan peningkatan keuntungan yang lebih besar pula bagi klaster maupun bagi IKM Namun hal tersebut menyebabkan penurunan keuntungan Karya Boga, maka peningkatan nilai $\mathrm{f}$ tersebut dianggap sudah tidak layak.Penentuan nilai $f$ dan perhitungan performansinya bagi produkproduk yang lain dilakukan dengan cara yang sama sehingga diperoleh hasil sebagai berikut:

\section{SIMPULAN}

Dengan menerapkan revenue sharing contract terjadi pembagian resiko antara IKM dan Karya Boga. IKM menetapkan harga jual yang rendah ke Karya Boga sehingga resiko biaya overstock di Karya Boga dapat diturunkan. Penurunan biaya overstock tersebut menyebabkan Karya Boga meningkatkan service level (CSL) sehingga meningkatkan jumlah pemesanannya $\left(Q^{*}\right)$. Dengan meningkatnya jumlah

Tabel.4. Performansi Revenue Sharing Contract pada Beberapa Nilai f untuk Produk Keripik Tahu

\begin{tabular}{|c|c|c|c|c|c|c|c|c|c|c|}
\hline \multirow[t]{2}{*}{$\mathbf{F}$} & \multirow[t]{2}{*}{$\mathbf{C u}$} & \multirow[t]{2}{*}{ Co } & \multirow[t]{2}{*}{ CSL* } & \multirow[t]{2}{*}{$\mathbf{Q}^{*}$} & \multirow{2}{*}{$\mathbf{E P}_{\text {IKM }}$} & \multirow{2}{*}{$\mathbf{E P}_{\mathrm{KB}}$} & \multirow{2}{*}{$\mathbf{E P}_{\text {Klaster }}$} & \multicolumn{3}{|c|}{$\begin{array}{l}\% \text { Profit dibanding mekanisme } \\
\text { awal }\end{array}$} \\
\hline & & & & & & & & IKM & Karya Boga & Klaster \\
\hline 0,05 & 18,5 & 10 & 0,65 & 7964 & 10.614 & 122.026 & 133.619 & 16 & 209 & 105 \\
\hline 0,1 & 17 & 10 & 0,63 & 7889 & 21.147 & 111.432 & 133.555 & 31 & 190 & 105 \\
\hline 0,15 & 15,5 & 10 & 0,61 & 7807 & 31.580 & 100.881 & 133.432 & 46 & 172 & 105 \\
\hline 0,2 & 14 & 10 & 0,58 & 7717 & 41.887 & 90.381 & 133.230 & 62 & 154 & 105 \\
\hline 0,25 & 12,5 & 10 & 0,56 & 7615 & 52.031 & 79.941 & 132.921 & 77 & 137 & 104 \\
\hline 0,3 & 11 & 10 & 0,52 & 7501 & 61.962 & 69.573 & 132.463 & 91 & 119 & 104 \\
\hline 0,35 & 9,5 & 10 & 0,49 & 7369 & 71.606 & 59.293 & 131.797 & 105 & 101 & 103 \\
\hline 0,4 & 8 & 10 & 0,44 & 7215 & 80.846 & 49.123 & 130.825 & 119 & 84 & 103 \\
\hline 0,45 & 6,5 & 10 & 0,39 & 7029 & 89.497 & 39.094 & 129.384 & 132 & 67 & 102 \\
\hline 0,5 & 5 & 10 & 0,33 & 6797 & 97.227 & 29.254 & 127.177 & 143 & 50 & 100 \\
\hline
\end{tabular}

Tabel 5. Performansi Revenue Sharing Contract untuk Semua Produk

\begin{tabular}{|c|c|c|c|c|c|c|c|c|c|}
\hline \multirow{2}{*}{$\begin{array}{c}\text { Kode } \\
\text { Produk }\end{array}$} & \multirow{2}{*}{$\begin{array}{c}f \\
(\%)\end{array}$} & \multirow[t]{2}{*}{ CSL } & \multirow[t]{2}{*}{$\mathbf{Q}^{*}$} & \multirow{2}{*}{$\begin{array}{c}\mathbf{E P} \\
\mathbf{I K M}\end{array}$} & \multirow{2}{*}{$\begin{array}{c}\mathbf{E P} \\
\mathbf{K B}\end{array}$} & \multirow{2}{*}{$\begin{array}{c}\mathbf{E P} \\
\mathbf{K L}\end{array}$} & \multicolumn{3}{|c|}{$\begin{array}{c}\% \text { Profit dibanding mekanisme } \\
\text { awal }\end{array}$} \\
\hline & & & & & & & IKM & KB & Klaster \\
\hline KTh & 35 & 0,49 & 7369 & 71.606 & 59.293 & 130.898 & 105 & 101 & 103 \\
\hline $\mathrm{KTp}$ & 26 & 0,54 & 3009 & 31.181 & 35.502 & 66.683 & 101 & 104 & 103 \\
\hline $\mathrm{KS}$ & 35 & 0,38 & 4786 & 32.057 & 21.250 & 53.306 & 102 & 105 & 103 \\
\hline SLD & 23 & 0,44 & 1973 & 9189 & 11.033 & 20.221 & 102 & 105 & 103 \\
\hline $\mathrm{KJ}$ & 28 & 0,44 & 126 & 2.423 & 2.440 & 4.863 & 104 & 103 & 103 \\
\hline $\mathrm{KcT}$ & 15 & 0,33 & 165 & 776 & 1.101 & 1.877 & 101 & 104 & 102 \\
\hline $\mathrm{KP}$ & 28 & 0,45 & 70 & 2.717 & 2.988 & 5.705 & 102 & 101 & 102 \\
\hline $\mathrm{BP}$ & 34 & 0,49 & 3956 & 39.189 & 36.510 & 75.699 & 102 & 100 & 101 \\
\hline
\end{tabular}


pesanan ternyata meningkatkan ekspektasi keuntungan baik bagi IKM maupun Karya Boga, sehingga ekspektasi keuntungan Klaster (sebagai supply chain) juga meningkat. Dari hasil penelitian diketahui semakin besar nilai f maka keuntungan IKM dan Klaster akan semakin besar namun sebaliknya keuntungan pada Karya Boga akan menurun. Sehingga perlu dilakukan penentuan nilai f yang tepat agar penerapan revenue sharing contract pada klaster industri makanan ringan ini mampu meningkatkan keuntunga IKM, Karya Boga dan Klaster. Untuk produk Keripik Tahu dengan menetapkan nilai fraksi (f) sebesar 35\% ternyata mampu menurunkan biaya overstock hingga $50 \%$. Akibatnya klaster berani meningkatkan service level dari 33\% menjadi 49\%, sehingga jumlah order (Q) Karya Boga meningkat sebesar 8\%. Pengingkatan jumlah order (Q) tersebut menghasilkan peningkatan keuntungan bagi IKM, Karya Boga dan klaster, masing-masing sebesar 5\%, $1 \%$ dan $3 \%$. Pada produk-produk yang lain dengan menetapkan fraksi pembagian keuntungan yang tepat, terbukti revenue sharing contract mampu meningkatkan keuntungan bagi IKM, Karya Boga Maupun Klaster sebesar 1\% hingga 5\%. Untuk menerapkan model ini kontrak diperlukan keterbukaan informasi antara IKM dan Karya Boga khususnya mengenai biaya yang terkait di masing-masing pihak.

\section{DAFTAR PUSTAKA}

Burt D., Dobler D., and Starling S., 2003. World Class Supply Management: The Key To Supply Chain Management, Seventh Edition, Mc Graw Hill, New York.

Cachon, G. and Lariviere M., 2005. Supply Chain Coordination with Revenue Sharing Contracts: Strengths and Limitation, Management Science, Vol. 51 No. 1, pp. 30-44.

Chopra, S. and Meindl P., 2001. Supply chain Management: Strategy, Planning, and Operation, Prentice Hall.

Dana, J. and Spier K., 2001. Revenue Sharing And Vertical Control In The Video Rental Industr, Journal. Industrial Economic Vol. 59. No. 3, pp 223-245.

Munnich Jr., Love, P. Warner J., Clark J., Templin E., Rosemeir D., and Lenhart N., 1999. Industry Clusters An Economic Development Strategy For Minnesota, Project Report, University of Minnesota.

Pasternack, B., 1985. Optimal Pricing And Returns Policies For Perishable Commodities, Marketing Science, Vol. 4, pp 166-176.

Taylor, T., 2002. Supply Chain Coordination Under Channel Rebates With Sales Effort Effects. Management Science. Vol. 48 No. 8, pp 992-1007.

Tsay, A.A. and Lovejoy W.S., 1999. The Quantity Flexibility Contract and Supply chain Performance, Manufacturing \& Service Operation Management, Vol. 1, No. 2, pp. 89-111.

Tsay, A.A., 1999. The Quantity Flexibility Contract and Supplier-Customer Incentives, Management Science, Vol. 45 no. 10, pp 1339-1358. 